\title{
Educação a distância: dificuldades dos tutores do primeiro curso licenciatura de ciências biológicas da Universidade Estadual de Maringá - PR
} Distance education: difficulties of the tutors of the first course of biological sciences of the University of State of Maringa - PR

Thaise Francielle de Sousa Roth Instituto Federal de Educação, Ciência e Tecnologia (Brasil)

Dulcineia Ester Pagani Gianoto Universidade Estadual de Maringá (Brasil)

\section{Resumo}

A educação a distância é uma modalidade de ensino que usa ferramentas da tecnologia de informação e comunicação para compartilhamento de informações. Essa organização permite a interação entre os participantes para a fim de obterem uma formação específica. A Universidade Estadual de Maringá iniciou as suas atividades nessa modalidade de ensino a partir de 2005, e em 2010, o curso de Licenciatura Ciências Biológicas na modalidade a Distância foi implantado. No referido ano, os tutores - presenciais e a distância iniciaram as suas atividades profissionais, com o desafio de utilizar as ferramentas e a dinâmica da plataforma online para auxiliar os alunos em sua formação. Esta pesquisa analisou os relatos dos tutores sobre a sua experiência com a primeira turma do curso de licenciatura em Ciências Biológicas na modalidade a distância da Universidade Estadual de Maringá. Foram utilizados questionários abertos respondidos pelos tutores atuantes e sua análise se baseou no instrumento de análise de conteúdo. Este trabalho de pesquisa buscou evidenciar quais as principais dificuldades encontradas para a atuação como tutor no Curso de Licenciatura em Ciências Biológicas, a fim de pesquisar e organizar planos de ações 
conjuntas que auxiliem no processo de ensino e aprendizagem desta modalidade. As principais dificuldades estão relacionadas com a limitação para a realização do trabalho, como por exemplo, relacionados aos materiais que podem ser postados e atividades promovidas, visto que se trata de um profissional com formação para tais atuações. Outro destaque está no estabelecimento desse profissional juntamente com a modalidade de ensino no Brasil.

Palavras-chave: educação a distância; tutores; ciências biológicas.

\begin{abstract}
Distance learning is a teaching modality that uses tools of information and communication technology for information sharing. This arrangement allows the interaction between among participants in the order to obtain specific training. The State University of Maringá started its activities in this modality of education from 2005, and in 2010, the Degree of Biological Sciences was deployed. In that year, tutors- face and distance began their professional activities in the course, with the challenge of using the tools and the dynamics of the online platform to assist the students in their training. This research examined the reports of the tutors about their experience with the first class of the degree course in Biological Sciences Degree Course in the order the distance of The State University of Maringá. Open questionnaires were used answered by active tutors and their analysis was based on content analysis tool. This research sought to highlight the main difficulties encountered in the work as a tutor in Biological Sciences Degree Course in order to search and organize plans of join actions to assist in the teaching and learning of this sport. The main difficulties are related to the limitation to carry out work, for example, related to materials that can be posted and promoted activities, since this is a professional trained in such performances. Another hightlight is the establishment of a trader along with the type education in Brazil.
\end{abstract}

Keywords: distance education; tutors; biology.

As instituições de ensino que oferecem cursos na modalidade a distância (EAD) têm a intenção de dar a oportunidade para os estudantes que vivem em regiões nas quais não existe a oferta dos cursos, visto que o Brasil é um país de proporções continentais e desenvolvimento concentrado nas regiões litorâneas, sul e sudeste. Sendo assim, tal modalidade de ensino foi idealizada a fim de atender principalmente adultos, os quais são trabalhadores que necessitam encontrar espaços de tempo alternativos para os estudos, entre 
suas atividades de trabalho e compromissos familiares. Portanto, é necessário ter uma estrutura organizacional, formação adequada da equipe de professores, tutores e coordenadores que possam promover um ensino apropriado ao estilo de vida desses estudantes.

Cardoso e Pereira (2010) fazem referência ao Decreto $n^{0} 5622 / 05$ que conceitua $\mathrm{EAD}$ como o processo de ensino e aprendizagem que ocorre por meio de TIC (Tecnologias da Informação e Comunicação), no qual os professores e alunos desenvolvem atividades educacionais em espaços físicos e em tempos diferentes. Essas atividades apoiamse no uso da internet, contribuindo para a propagação de formas alternativas de gerar conhecimento e, também, para a formação no ensino superior.

Num contexto de mudanças econômicas e educacionais, a Educação a Distância reaparece no cenário educacional como alternativa à democratização da educação (Cardoso e Pereira, 2010). Essa educação é diferenciada pela possibilidade de realizar processos de aprendizagem baseados na autodeterminação e autonomia dos alunos, o que, de certa forma, pode lhes propiciar condições de decidir sobre seu estudo por iniciativa própria (Peters, 2009). Assim, a autonomia refere-se ao ritmo, ao tempo e ao método de estudo individual desenvolvido pelo aluno.

A proposta de diretrizes para a formação inicial de professores da educação básica aprovada em 2001 (Brasil, 2001), na qual estão incluídos professores atuantes nas disciplinas de Ciências do Ensino Fundamental II ( $6^{\circ}$ ao $9^{\circ}$ ano) e de Biologia ( $1^{\mathrm{a}}$ a $3^{\mathrm{a}}$ série do Ensino Médio), torna obrigatória a formação em cursos de nível superior. Dados baseados no INEP (Instituto Nacional de Estudos e Pesquisas Educacionais) mostram que 30,22\% dos professores atuantes na região sul não possuem formação legal exigida para a função, Licenciatura plena na área específica. Portanto, apresenta-se a modalidade de Educação a Distância como a mais adequada para tais destinatários, já que são adultos trabalhadores, com responsabilidades familiares (Machado, Castro, Filho, Lepri, Andrian, Pamphile, De Mello, Ferrarese, Torrezan e Vicentini, 2009). Sendo assim, a autonomia e 
flexibilidade nos horários de estudo, permite a dedicação aos estudos aos fins de semana, nos intervalos de trabalho e outros.

Tendo em vista o histórico apresentado, vislumbrou-se a possibilidade de formação no ensino superior promovida pela EAD. Sendo assim, em virtude do lançamento pelo MEC (Ministério da Educação e Cultura) em 2005 do Programa de Formação Inicial para Professores em Exercício no Ensino Fundamental e no Ensino Médio - Pró-Licenciatura - Fase II, foi eminente a necessidade de capacitar professores da educação básica. Dessa forma, para atender a essa necessidade, o Centro de Ciências Biológicas nomeou a Comissão para Elaboração do Projeto Pedagógico do Curso de Licenciatura em Ciências Biológicas na Modalidade a distância (Portaria nº 035/2005CCB).

Ainda neste mesmo ano, a Universidade Estadual de Maringá (UEM), conforme a resolução 119/2005, aprovou as normas de organização e funcionamento de cursos de graduação na modalidade a distância (Machado, Castro, Filho, Lepri, Andrian, Pamphile, De Mello, Ferrarese, Torrezan e Vicentini, 2009).

Em 22/02/2006, pela portaria $\mathrm{n}^{0}$ 07, foi liberado, nos moldes da UAB (Universidade Aberta do Brasil) aprovado pelo MEC/ CAPES (Coordenação de Aperfeiçoamento de Pessoal de Nível Superior), o início da formatação do curso de Ciências Biológicas na modalidade a distância, de acordo com as exigências internas da UEM. Posteriormente, em agosto de 2008, esse projeto foi aprovado pelo MEC/CAPES, iniciando a sua revisão para a aprovação nos diferentes conselhos.

A previsão inicial foi ofertar o curso de Ciências Biológicas na modalidade a distância em 6 Polos localizados nas seguintes cidades do Estado do Paraná: Astorga, Cidade Gaúcha, Goioerê, Nova Londrina, Sarandi e Umuarama. Concretizada a previsão, o processo seletivo ocorreu em 2009, e em 2010 foi iniciado o primeiro ano do curso de Licenciatura de Ciências Biológicas, na modalidade a distância, da Universidade Estadual de Maringá, com o tempo de duração de 4 anos. No ano de 2013 a primeira turma de licenciados foi graduada. 
Para a realização desta pesquisa, foi aplicado um questionário para coletar as opiniões dos tutores presenciais e a distância em relação a escolha pela modalidade a distância para trabalhar, dificuldades para o desenvolvimento de suas atividades como tutor, dificuldades no uso da plataforma online MOODLE1 (Modular Object Oriented Distance Learning), qualidade dos materiais fornecidos aos alunos pela UEM (impressos e online), metodologias de ensino (vídeo-aulas, webconferências e fóruns), etc.

Esse questionário teve como objetivo evidenciar as características das principais atividades desenvolvidas nessa modalidade de ensino, conforme os relatos dos tutores, como por exemplo, a utilização das ferramentas de ensino online e offline (webs, vídeo-aulas, fóruns, material impresso, etc.) e de apoio pedagógico, disponibilizados para a formação dos alunos (tutores, assessoria via MOODLE). Ferramentas essas, até então, nunca utilizadas para a formação de licenciados em Ciências Biológicas da UEM.

Após a reflexão sobre esses dados esperamos ser possível repensar o desenvolvimento dessas atividades no ensino da modalidade a distância, a fim de atender aos alunos de forma eficaz, promovendo uma formação adequada para sua atuação profissional, como professores de Ciências e Biologia da Educação Básica do país.

\section{ORGANIZAÇÃO E FUNCIONAMENTO DO CURSO NA MODALIDADE A DISTÂNCIA DA UNIVERSIDADE ESTADUAL DE MARINGÁ}

Nas cidades que ofertam os cursos a distância pela UEMé obrigatória a existência de um polo de apoio presencial. Trata-se de estruturas às quais são gerenciadas pelas prefeituras das cidades, normalmente em espaços físicos associados a escolas municipais, ou então os polos são construídos especificamente para atender os alunos da EAD. Nesses espaços, é obrigatório um laboratório de informática com o número de computadores suficientes para atender os alunos do polo, sala com projetor multimídia para a transmissão das webs conferências, realizadas e transmitidas pelo estúdio de EAD do campus sede da UEM em Maringá, além de salas de aula para a aplicação de avaliações 
presenciais. Também é obrigatório contar com o tutor presencial e a distância, os quais pelas especificações da CAPES (2013) possuem as seguintes atribuições:

- Mediar a comunicação de conteúdos entre o professor e os estudantes;

- $\quad$ Acompanhar as atividades discentes, conforme o cronograma do curso;

- Apoiar o professor da disciplina no desenvolvimento das atividades docentes;

- Manter regularidade de acesso ao Ambiente Virtual de Aprendizagem - AVA e responder às solicitações dos alunos no prazo máximo de 24 horas;

- $\quad$ Estabelecer contato permanente com os alunos e mediar as atividades discentes;

- Colaborar com a coordenação do curso na avaliação dos estudantes;

- $\quad$ Participar das atividades de capacitação e atualização promovidas pela instituição de ensino;

- Elaborar relatórios mensais de acompanhamento dos alunos e encaminhar à coordenação de tutoria;

- $\quad$ Participar do processo de avaliação da disciplina sob orientação do professor responsável;

- $\quad$ Apoiar operacionalmente a coordenação do curso nas atividades presenciais nos polos, em especial na aplicação de avaliações.

Para acessar o ambiente online do curso, os alunos precisam de um login fornecido pela instituição ao realizar a sua matrícula. Nesse ambiente, a UEM posta as vídeo-aulas das disciplinas em andamento, todas elas organizadas e ministradas por professores da área específica do conhecimento. Ademais, existem fóruns promovidos pelos tutores a distância, nos quais são criados tópicos de discussões referentes aos capítulos discutidos pelos professores nas vídeo aulas da disciplina. Trata-se de uma plataforma online na qual estão disponíveis os 
materiais didáticos para a formação dos alunos (vídeo aulas, fóruns e materiais impressos), comunicados administrativos e da programação do curso (datas de avaliações e de webconferências, conteúdo programático das disciplinas, sua duração, etc.).

Durante a realização das disciplinas, algumas atividades são solicitadas pelos professores, atividades em postagem de arquivos únicos, fóruns, respostas das perguntas realizadas durante as vídeoaulas, e instruções para seminários ou atividades práticas que também podem ser apresentadas e avaliadas pelo tutor presencial, conforme a solicitação do professor.

Para auxiliar no processo de elaboração e execução das atividades acadêmicas do Curso a Distância de Licenciatura em Ciências Biológicas da UEM, existem dois coordenadores: o Coordenador de Curso e o Coordenador de tutoria. Sendo assim, o Coordenador de Curso tem a função de acompanhar e avaliar as atividades acadêmicas, participar das atividades de capacitação e atualização promovidas pelas UEM (desenvolvimento de metodologias, materiais e modelos de avaliação dos alunos), planejar e desenvolver atividades de seleção e capacitação de profissionais envolvidos no curso, participar de eventos da área, acompanhar as atividades dos professores, do coordenador de tutoria e dos coordenadores de polo, informar à UAB os bolsistas que estão aptos ao recebimento de bolsas e auxiliar a coordenação da UAB na elaboração da planilha financeira do curso. Já o Coordenador de Tutoria tem a função de orientar, acompanhar e avaliar os tutores presenciais e a distância, estar em contato com os polos, criar relatórios, planejar o calendário acadêmico, acompanhar o desempenho dos tutores e alunos, coordenar o processo de seleção e quando solicitado auxiliar nos planejamentos de aulas dos professores.

Com o propósito de monitorar e aperfeiçoar os trabalhos realizados pelos profissionais que atuam na modalidade de ensino, periodicamente, realizam-se reuniões dos tutores presenciais e a distância com a Coordenação de tutoria e de Curso. Esse espaço serve para coletar as opiniões e perspectivas sobre trabalho de tutoria e discutir sobre elas. Sendo assim, durante uma dessas reuniões aplicouse um questionário aos tutores presenciais e a distância do curso. Nesse 
questionário, os tutores descreveram a sua perspectiva e avaliaram as atividades propostas pela UEM para a formação dos alunos, assim como especificidades sobre a realização de seu trabalho como tutor.

Considerando a rotina acadêmica dos alunos e do trabalho dos tutores no curso de EAD, este artigo tem por objetivo analisar as informações fornecidas pelos tutores, a fim de obter elementos que auxiliem na reorganização dos espaços formativos dos alunos do curso de Ciências Biológicas na modalidade a distância, como por exemplo: diretrizes de elaboração de materiais, confecção das vídeo aulas e produção de webconferências, especificações dos trabalhos solicitados pelos professores, métodos de avaliação, etc. Os dados desta pesquisa representam o processo de complementação das diretrizes de trabalho do curso nessa modalidade no Brasil e na UEM.

\section{METODOLOGIA PARA A COLETA E ANÁLISE DE DADOS}

Para esta pesquisa, os sujeitos foram escolhidos de forma proposital em função de suas características ou de seus conhecimentos sobre as questões de interesse da pesquisa (Alves e Mazzotti, 1988), para saber quais foram as principais dificuldades para atuação da tutoria no primeiro Curso de Licenciatura em Ciências Biológicas na modalidade EAD. Assim, os participantes da pesquisa são tutores presenciais e a distância do Curso de Ciências Biológicas oferecido pela UEM, totalizando 9 tutores entrevistados, 6 presenciais e 3 a distância. Tratase de uma pesquisa qualitativa de caráter descritiva, a qual consistiu em uma série de planejamentos, no caso, na construção e validação do questionário aplicado, ao ser aplicado em um primeiro grupo de tutores atuantes em outro curso, discutidos em outras reuniões pelos coordenadores. Além da execução, tempo destinado aos tutores durante a reunião para que respondessem ao questionário.

As respostas foram coletadas em abril de 2013, referentes às atividades realizadas pelos tutores desde o início de sua contratação pela UEM. Essas informações foram sistematicamente submetidas à observação, reflexão e interpretação por parte dos pesquisadores (Bogdan e Biklen, 1994; Fiorentini e Lorenzato, 2006). 
Após o preenchimento do questionário, os dados qualitativos foram analisados pela técnica de análise de conteúdo, a qual consiste no recorte de temas emergentes de interesse da pesquisa presentes nas respostas dos tutores ao questionário (Bardin, 2004). Esses dados também foram organizados por temas, originando a sua categorização construída ao longo da análise, para a exposição e discussão pelas pesquisadoras. Segundo Flick (2004), criam-se unidades de codificação, ou seja, menor elemento de material que é possível analisar, a parte mínima do texto que pode ser enquadrada em uma categoria.

\section{O PERFIL DOS TUTORES DO CURSO DE CIÊNCIAS BIOLÓGICAS DA MODALIDADE A DISTÂNCIA DA UNIVERSIDADE ESTADUAL DE MARINGÁ}

Dos tutores entrevistados, 6 eram tutores presenciais e 3 a distância, com idades que variaram entre 28 a 41 anos, sendo apenas 2 do sexo masculino e 7 do sexo feminino. O regime de tutoria é realizado conforme a necessidade da Universidade, sendo assim, a primeira seleção de tutores ocorreu para o início do funcionamento do curso. Os 3 tutores a distância em exercício são dessa primeira seleção, ou seja, com mais de 3 anos de experiência em tutoria. Porém, ao longo do curso alguns tutores presenciais desistiram do cargo e novos processos seletivos foram realizados, justificando a variação do tempo de experiência dos tutores que participarem dessa pesquisa de 3 meses a 3 anos.

Sendo assim, atualmente o Curso de Ciências Biológicas na modalidade EAD conta com 3 tutores a distância para atuar em 6 polos, portanto cada tutor está responsável por 2 polos e não apenas por um, como no início das atividades de tutoria. Essa situação ocorreu pelo fato de alguns tutores à distância, desistirem do cargo e alguns alunos desistirem do curso, sendo assim, o resultado da somatória da quantidade de alunos em 2 polos ainda está dentro da margem máxima de atendimento de cada tutor, 25 alunos. 
O abandono do trabalho de tutoria pode estar relacionado ao regime legal da profissão de tutor, visto que, se o tutor se afastar de sua função, o pagamento de sua bolsa não é realizado, pois não há regulamentação legal para função de tutor. Sendo assim, conforme Tonetti (2012) por não contar com o registro em carteira de trabalho, como bolsistas, os tutores ficam marginalizado dentro da esfera legal de exercício de sua função, e esse fato pode ser determinante na permanência do tutor em seu cargo.

O nível de formação de todos os tutores entrevistados é de pósgraduação, com especializações, mestrados e doutorados distribuídos nas áreas de educação, tecnologia e meio ambiente. Todos eles afirmaram procurar o trabalho como tutor para conhecer a área de trabalho na educação a distância, uma área em desenvolvimento no Brasil, ou seja, adquirir novas experiências de trabalho em um ramo em expansão.

\section{O USO DOS RECURSOS EDUCACIONAIS UTILIZADOS PARA O TRABALHO DE TUTORIA NO CURSO DE LICENCIATURA EM CIÊNCIAS BIOLÓGICAS E FORMAÇÃO DOS ALUNOS EM EAD}

A Universidade Estadual de Maringá oferece o curso na modalidade a distância desde o ano de 2005, com o apoio pedagógico e recursos educacionais exclusivos para atender tal modalidade. Esses recursos são oferecidos pela UEM em parceria com as prefeituras das cidades em que os polos de apoio presenciais se encontram. Foram descritas pelos tutores entrevistados a interação com os serviços oferecidos pela UEM (ambiente de trabalho pela plataforma MOODLE, material impresso, vídeo aulas, web conferência, fóruns de discussão), além do uso da internet para a realização de seu trabalho.

\section{Plataforma MOODLE}

Os entrevistados alegaram que não tiveram dificuldades para se adaptar a utilização da plataforma para as realizações de seu trabalho como tutor. Porém, as limitações de ações dentro plataforma MOODLE 
impedem de exercer sua função de tutor com maior eficiência e agilidade, como por exemplo, as restrições quanto às postagens na plataforma, na qual a capacidade para o envio de arquivos anexados para serem postados pelos tutores é muito reduzida.

Trata-se de um ambiente de aprendizagem no qual poderia ser caracterizado como aprendizagem colaborativa. Segundo Torres e Irala (2007) a aprendizagem colaborativa tem o potencial de promover uma aprendizagem mais ativa por meio de: estímulos ao pensamento crítico; atividades que desenvolvam a capacidade de interação, negociação de informações e resolução de problemas; promoção da capacidade de autor regulação do processo de ensino-aprendizagem. Essas formas de ensinar e aprender tornam os alunos mais responsáveis por sua aprendizagem, levando-os a assimilar conceitos e a construir conhecimentos de uma maneira mais autônoma. Tais propostas trazem de forma intrínseca concepções sobre o que é ensino, aprendizagem e qual a natureza do conhecimento, principalmente por se tratar da modalidade EAD. Uma das ideias fundamentais que elas encerram é a de que o conhecimento é construído socialmente, na interação entre pessoas, ao trocarem informações e concepções a respeito do conteúdo que está sendo discutido e não pela transferência do professor para o aluno.

Portanto, limitar as postagens realizadas pelos tutores é limitar a possibilidade de disponibilizar aos alunos formas alternativas de conduzir os seus estudos, assim como o acesso a outros materiais que poderiam auxiliá-los no processo de construção de seu conhecimento. Tal fato, também observado por Souza (2014) ao relatar que os tutores foram capacitados para esse fim, dentro das suas limitações de perfil e atuação, sendo conscientizados sobre as diferenças do trabalho desenvolvido no ambiente virtual, ao qual incentivam o hábito da pesquisa, esclarecem dúvidas e mantêm o contato com os estudantes e equipe pedagógica do curso. Os tutores apresentam formação adequada para a seleção de materiais confiáveis e de qualidade para esse processo. Assim como, a promoção de tópicos do conteúdos programáticos que julgarem relevantes, sem necessariamente fazer 
parte de uma ação idealizada, organizada e realizada pelo professor que ministra a disciplina.

Quanto aos comandos e a navegação pela plataforma, os tutores apresentaram outras limitações à sua função, como por exemplo, acesso a informações de alunos, como notas, quais disciplinas estão em dependência e quais alunos estão online na plataforma. Tais possibilidades permitiriam aos tutores agilidade para complementar os outros serviços oferecidos pela Universidade. Assim como, providenciando ações de monitoramento e auxílio aos alunos sob sua responsabilidade de formação.

Como apresentado por Tonetti (2012) existem modelos que tratam o tutor como professor-tutor, no qual ele apresenta mais autonomia para a condução de suas atividades, visto que é permitida a elaboração de suas próprias atividades didáticas e com a possibilidade de modificá-las no interior dos cursos que ministra. Porém, em outros modelos, como no adotado pelos tutores envolvidos nesta pesquisa, o papel do professor tutor o qual se configura basicamente na correção e orientação dos alunos, ainda que possa fazer propostas para o professor autor, ele não pode modificá-las diretamente e está sujeito a um agente quase sempre alheio ao contato com os estudantes. Portanto, o tutor tem o papel de "averiguador de tarefas ou acessos", como podemos observar na mensagem de uma tutora a um aluno, relatada em Tonetti (2012, p. 9):

Estou passando para lembrá-lo que você deve acessar a plataforma e todas as disciplinas com frequência, pois tenho percebido que você está ausente há alguns dias. Cuidado para não perder o prazo de entrega das atividades. [sic]

Essa preocupação também é apontada por Tonetti (2012), no qual o papel do tutor é muitas vezes mais burocrático que pedagógico. É nesse sentido que são legítimas as críticas que acusam a EAD de autoinstrução, já que temos sido incapazes de gerenciar modelos em que haja interação, visando crescimento pedagógico, efetivamente ocorra no interior dos AVA (Ambientes Virtuais de Aprendizagem), como resultado efetivo de uma relação ou interação entre docentes e 
discentes - o que não significa que devamos negar os casos em que a EAD tem apresentado sucesso no que diz respeito à construção de novas práticas de comunicação e interação.

Sendo assim, a plataforma online pode ser melhorada com a opinião de seus usuários, considerando que ela facilita a obtenção de informações necessárias para os estudos dos alunos e o trabalho dos tutores, assim como informativos do curso, visualização de notas e comunicação entre professores, tutores e alunos de outros polos que cursam Ciências Biológicas. Dessa forma, a plataforma seria utilizada em sua capacidade máxima, potencializando a eficiência do curso na modalidade a distância.

\section{Material impresso}

A criação do material didático faz parte da proposta pedagógica da UEM para os cursos de EAD, um dos itens obrigatórios dos serviços disponíveis para a promoção do curso nessa modalidade. Para isso, os coordenadores do curso entram em contato com os professores interessados na produção desse material, os quais, em algum momento, podem ou não ser os docentes da disciplina. A respeito desse material, os tutores afirmaram ter acesso pela plataforma e é possível visualizá-lo no formato PDF (Portable Document Format). Assim como, alegaram que consultam o material apenas para esclarecer algumas dúvidas dos alunos sobre o seu conteúdo, sentido de frase, etc. Porém, segundo os tutores esses materiais não atendem as necessidades de um aluno que estuda sem o acompanhamento imediato do professor, visto que não atendem as dúvidas mais complexas dos alunos e a maioria deles utilizam esse material como única fonte de informações para os estudos.

Portanto, reforçamos novamente o que foi evidenciado por essa pesquisa, a necessidade que os tutores sentem em ter maior liberdade de atuação, abrindo a possibilidade da criação de um ambiente de aprendizagem colaborativa para esse curso, auxiliando os alunos em como obter diversas fontes de informações confiáveis para a construção de seu conhecimento. 


\section{Vídeo-aulas}

Conforme Machado, Castro, Filho, Lepri, Andrian, Pamphile, De Mello, Ferrarese, Torrezan e Vicentini (2009), as vídeoaulas são gravações realizadas pelos professores abordando e discutindo os conteúdos a serem estudados, na área de conhecimento do assunto da disciplina. Geralmente usando como base o material impresso que pode ser ou não de autoria dos professores. Sendo assim, é de responsabilidade da UEM, por meio da coordenação do curso de Ciências Biológicas a Distância, contatar os professores, perguntando o seu interesse e disponibilidade para ministrar a disciplina, bem como para gravar as vídeo-aulas.

As vídeo-aulas são postadas conforme o término de sua edição pelo setor de apoio do núcleo da EAD. Os tutores alegaram que visualizam rapidamente as vídeo-aulas conforme elas são postadas e as utilizam para sanar dúvidas dos alunos. Dos 9 tutores entrevistados, 3 alegaram que as vídeo-aulas são ótimas e que ajudam os alunos a compreender melhor o material disponível na plataforma. Porém, os outros 6 tutores usaram essa mesma justificativa como crítica às vídeo-aulas. Para eles, os professores ficam presos ao material e à metodologia expositiva durante as gravações. Eles sugerem que outras metodologias de ensino deveriam ser desenvolvidas pelos professores e que poderiam ficar mais desinibidos ao fazer as gravações das vídeo-aulas, interagindo com os alunos, propondo algumas reflexões durante as aulas, a fim de aproximar os alunos com os objetivos da disciplina e sua importância para a compreensão da Biologia.

Os professores são os mesmos professores da graduação da modalidade presencial, os quais precisam se organizar para cumprir a carga horária já ministrada no ensino presencial, além do planejamento e desenvolvimento da disciplina na modalidade a distância. Lembrando que os educadores não recebem qualificação pedagógica pela universidade para trabalhar com produções direcionadas para a educação a distância, sendo que tudo que foi feito, até então, é da organização pessoal e criação do professor. Alguns deles procuram adaptar as estratégias pedagógicas convencionais aplicadas no presencial para a modalidade a distância e percebem que esses 
espaços necessitam de novas abordagens específicas para atender adequadamente aos alunos. Para tanto, estão começando a definir ou redefinir os métodos de ensino e aprendizagem para uma educação eficaz a distância (Peters, 2009).

Percebe-se uma grande dificuldade quando os professores do Ensino Superior buscam trabalhar com tecnologias virtuais, pois todos estudaram em escolas e universidades convencionais, onde aprenderam e adquiriram habilidades comuns de um ensino expositivo e de aprendizagem receptiva. Com isso, esses professores acreditam que estas habilidades e estratégias são ideais e acabam reproduzindoas no ensino a distância. Entretanto, geralmente, não atingem os mesmos resultados.

\section{Webconferências}

No Projeto Político-Pedagógico do Curso de Ciências Biológicas, a estrutura das disciplinas está configurada como modular, com temas específicos a serem abordados em um determinado espaço de tempo. A programação do trabalho realizado por uma disciplina está baseada em: material impresso confeccionado pelos professores das disciplinas, capítulos discutidos em vídeo-aulas, fóruns de discussão e a organização de web conferencias. As webconferências normalmente são realizadas logo nos primeiros dias em que a disciplina se inicia, além de um segundo momento para a sua finalização, normalmente antes da realização das avaliações presenciais.

As webconferências são ministradas pelos mesmos professores e com o mesmo formato em vídeo, porém elas se diferenciam por ser o momento de contato direto em tempo real dos alunos com o docente, uma oportunidade para construir uma aula integrada, já que todos os alunos de todos os polos estão conectados ao mesmo tempo. Os tutores alegaram participar de todas as webs e, segundo eles pouco contribuem para a formação dos alunos, visto que o tempo de interação não é aproveitado. E o mais importante nesses encontros ao vivo é fazer uma explanação geral do conteúdo, deixando claro o que se espera que o aluno compreenda do assunto. Além disso, o tempo de duração da web 
também foi criticado pelos tutores, afinal muitos alunos se descolocam quilômetros para chegar até o polo e se decepcionam em ter, algumas vezes, apenas 40 minutos de web.

\section{Fórum de discussão}

A aprendizagem autônoma e o estudante do futuro foram temas de discussão em Belloni (2003), nos auxiliando na compreensão de que o ensino na educação a distância é centrado no aprendiz, capaz de auto-dirigir e auto-regular esse processo. Esse modelo de ensino é apropriado a adultos com maturidade e motivação necessárias a auto-aprendizagem, possuindo o mínimo de habilidades de estudo (Trindade, 1992; Carmo, 1997, apud Belloni). Portanto, para a realização de um curso a distância são necessárias características adquiridas com a experiência de vida. Assim, para realizar a troca de ideias dos alunos existe o fórum de discussão online organizados pelos tutores a distância. Normalmente, eles são divididos conforme as vídeo-aulas dos professores, ou então por atividades propostas, como realização de pesquisas, coleta de materiais, estudo por questionários, etc.

Todos os tutores alegaram realizar a leitura dos fóruns de discussões com a intenção de saber o que é discutido pelos alunos, quais são as dúvidas mais frequentes, utilizando essas informações para julgar o que pode ser feito para ajudá-los. Os 3 tutores a distância disseram estimular os alunos a participarem dos fóruns, mas observam que poucos participam, mesmo com a possibilidade do fórum se tornar um ambiente de construção de conhecimento. As sugestões dos tutores estão relacionadas a viabilidade de atribuir nota à participação dos alunos nos fóruns, visto que o ambiente, atualmente, é caracterizado apenas como troca de respostas para as atividades que são propostas pelos professores. E raramente existe uma discussão reflexiva sobre o assunto, ou seja, poucos são os momentos em que os alunos refletem e produzem efetivamente para a construção do conhecimento. 


\section{Relações dos tutores com sua função e local de trabalho}

Alguns aspectos sobre a relação dos tutores com seu local de trabalho também foram citadas no questionário aplicado. No caso, todas as perguntas foram realizadas para ambos os tutores, porém os detalhes sobre o polo e o uso da internet para auxiliar os alunos, ficaram restritos, respectivamente, aos tutores presenciais e tutores a distância.

Ao responder sobre o significado que o polo tinha para eles, os tutores responderam que entendem o polo como um local para reunir os alunos, com a função de facilitar os estudos, é onde ocorre a troca de calor humano. O polo é a estrutura física fornecida pelas prefeituras da cidade e sua estrutura é variada conforme os recursos destinados a esse fim. Portanto, nos 6 polos de apoio presencial, local no qual o curso é oferecido, foi possível observar como os tutores observam a relação do polo e seus alunos. Trata-se do porto seguro acadêmico para os alunos, afinal o polo é uma extensão da universidade e deve representar a formação de qualidade que a UEM oferece, sempre que necessitarem, o tutor presencial estará próximo fisicamente, a fim de auxiliar os alunos e suas dúvidas acadêmicas, assim como nas frustações, angústias, conquistas adquiridas nesse processo de aprendizagem. Porém, em alguns depoimentos os tutores revelaram faltar estrutura física dos polos para comportar os alunos, como por exemplo, salas para apresentação de trabalhos, estudos ou uma biblioteca de acesso fácil aos alunos.

Quando questionados sobre como viam a sua função de tutor, alguns fizeram referência a um dos itens determinados pela UEM, ou seja, os tutores são a ponte de comunicação entre o aluno e o professor. Muitas atividades desenvolvidas pelos tutores presenciais e a distância estão descritas no Projeto Político-Pedagógico do Curso:

Tutores (presenciais, a distância): com formação acadêmica em Ciências Biológicas ou áreas afins, atuando no Polo de Apoio Presencial, ou na Instituição. Têm a função de acompanhar, apoiar e avaliar os estudantes em sua caminhada. Recebem formação em EAD antes de iniciarem suas atividades e ao longo do curso. Atuam sob a supervisão de um Coordenador 
de Tutoria, função ocupada por um professor do Departamento de Biologia (Machado, Castro, Filho, Lepri, Andrian, Pamphile, De Mello, Ferrarese, Torrezan e Vicentini, 2009).

Sendo assim, em cada uma das cidades que apresentam polo de apoio presencial de educação a distância, para cada turma de 25 alunos, é obrigatória a presença de um tutor presencial. Também cabe a esse tutor a aplicação das avaliações presenciais, acompanhamento das web conferências, organização de grupos de estudos, avaliações de apresentações de seminários, acompanhamento dos estágios realizados, organização e zelo de todas as atividades realizadas no polo de apoio presencial. Já, o tutor a distância presta os seus serviços na plataforma MOODLE, organizando fóruns de discussão para esclarecer: os conteúdos das web conferências e vídeo-aulas, a realização dos trabalhos práticos, as dúvidas de exercícios, além das correções das avaliações presenciais e atividades propostas pelos professores que são gerenciadas suas postagens e prazos pela plataforma.

Em alguns momentos, os comentários se assimilavam conforme a modalidade de tutoria exercida, ou seja, a atuação e comunicação do tutor a distância se dá exclusivamente pela internet. O tutor presencial também tem acesso à plataforma, porém sua função e a organização de como realizá-la está vinculada ao polo de apoio presencial. Por exemplo, os depoimentos dos tutores a distância sobre a importância do interesse do professor da disciplina em se relacionar com eles, uma vez que consideram essa ponte de comunicação como essencial para o trabalho do tutor a distância. Já os tutores presenciais enfatizaram o seu trabalho com a emoção, alegando a necessidade de amparar, direcionar, incentivar os alunos para que não desistam do curso, ajudar a desenvolver um pensamento crítico e uma organização acadêmica de formação.

Para ilustrar o que poderia ser feito para melhorar o desempenho de sua função, os tutores novamente comentaram sobre o acesso às notas dos alunos, para que o atendimento de cada aluno seja rápido e específico. As notas são lançadas no sistema e enviadas ao polo pela secretaria acadêmica do curso, o processo entre a digitação das notas e a publicação nos polos depende das atividades do coordenador do 
polo em imprimir e publicar o edital. Quando os tutores têm acesso a essas notas, é possível diagnosticar a situação acadêmica do aluno e planejar a melhor maneira auxiliá-lo individualmente, para que ele avance e prossiga com o processo de avaliação. Além disso, sugeriram que o contrato de trabalho do tutor deveria ser prolongado para que o acompanhamento dos alunos seja mais próximo, visto que os tutores que entraram há pouco tempo, declaram estar desconfortáveis em trabalhar com alunos que estão terminando o curso. Não conhecem os alunos o suficiente para auxiliá-los nos momentos finais da formação. Outro aspecto citado como apoio para a função de tutor está relacionado com o hábito dos alunos em procurar os tutores para auxiliá-los. Eles declararam que essa procura é muito pequena e por isso a frequência ao polo, em algum momento, deveria ser obrigatória.

O fato de poucas atividades serem obrigatórias para os alunos da EAD nos auxiliam na compreensão das maiores dificuldades para realizar o trabalho de tutor. Os entrevistados comentaram que a maioria dos alunos são descomprometidos com os estudos, não procuram ajuda. Além disso, essa falta de compromisso também foi observada em alguns professores que ministram as disciplinas, os quais segundo os tutores, "não levam a EAD a sério". Além disso, a estrutura dos polos também foi apontada como um fator que dificulta o trabalho do tutor, visto que alguns polos não apresentam laboratórios para os estudos com microscopia, reagentes químicos, etc. Assim como, não existem locais apropriados para conversar com os alunos no polo.

A falta de compromisso com os estudos acadêmicos pode estar relacionada com o que Barrenechea (2003) observou ao apontar que os frequentadores da educação a distância são pessoas adultas, as quais trabalham e possuem renda média baixa. São pais e mães de família, que possuem responsabilidades estendidas à igreja e comunidade, e/ou pararam de estudar a algum tempo, sofrem de ansiedade em relação à retomada de seus estudos, uma vez que seu contexto de vida e trabalho são voltados para a subsistência e, por isso, tendem a serem pessoas pragmáticas.

O trabalho do tutor envolve descobrir maneiras diferentes de abordar os alunos e chamar a atenção para a sua forma de se organizar 
para estudar, assim como a observação da forma com que o conteúdo está sendo abordado pelo professor. Portanto, ao ser perguntado aos tutores quantas horas por semana eles se dedicam aos estudos para ser tutor, a maioria deles respondeu que o tempo todo que está se dedicando as atividades de tutoria: ao visualizar as vídeo-aulas, acompanhar as discussões dos fóruns, corrigir avaliações e buscar informações dos quais os alunos irão necessitar. Ou seja, não existe uma formação específica que o tutor possa apresentar para conseguir realizar o seu trabalho de atendimento específico a alunos da EAD.

Em nenhum momento os tutores relataram a necessidade de uma formação específica em EAD para a realização da função de tutoria, visto que a exigência do edital de contratação é a experiência em atuar como professores, sendo assim, a única necessidade formativa específica em EAD foi adquirida no decorrer da realização de seu trabalho, aprendendo como superar as dificuldades apontadas por essa pesquisa. Em um trabalho similar, Cabanas e Vilarinho (2007) perceberam que os tutores entrevistados consideraram ser professor como pré-requisito essencial da tutoria ou então já ter sido monitor no ensino presencial. Ao analisar essas concepções, entendemos que o processo de construção da identidade do profissional tutor está em andamento e a necessidade formativa deve se basear principalmente na habilidade de diagnosticar e acompanhar as atividades e dificuldades dos alunos exclusivos da modalidade de ensino a distância. Além de conseguir realizar o trabalho necessário utilizando a tecnologia disponível. Porém, essa necessidade não vem atrelada ou serve de garantia quando o tutor tem experiência no exercício da profissão de professor.

A relação dos tutores com a internet foi especificada principalmente pelo acesso à plataforma MOODLE. A maioria alegou que acessa a plataforma fora do horário de trabalho e que também realiza pesquisas na internet para complementar seu trabalho de tutoria. Procuram artigos, livros, imagens que possam auxiliar os alunos em suas dúvidas sobre o conteúdo. Além disso, relataram pesquisar como poderiam organizar as atividades em grupo e orientar os alunos a resolver as atividades propostas pelo curso. 
A relação dos tutores com os alunos e com a formação na EAD também foi levantada, os tutores consideram os alunos da EAD como alunos com a capacidade para serem dedicados, esforçados, maduros e experientes por serem adultos. Porém, alguns alunos demonstraramse interessados em obter um diploma e não uma formação. Além disso, perceberam que alguns deles entraram no curso com a ideia de que o curso seria facilitado por ser na modalidade a distância e logo perceberam que não era isso e desistiram.

Os tutores veem a formação na EAD como uma oportunidade para os alunos que não tem possibilidade de realizar um curso presencial, além de terem a oportunidade de assistir as aulas quantas vezes acharem necessário, nos momentos que lhes for confortável. Porém, a maioria deles não se adapta à metodologia de ensino e à necessidade de autoconhecimento e disciplina necessária para sua formação.

Além disso, os tutores foram questionados sobre as mudanças que eles acreditam que melhorariam a modalidade de ensino. Primeiramente existe a necessidade dos professores se especializarem no ensino a distância, com o conhecimento para desenvolver novas metodologias de ensino, assim como, a melhoria na estrutura dos polos, com bibliotecas com materiais de qualidade acessíveis aos alunos e laboratório.

\section{CONSIDERAÇÕES FINAIS}

Ao optarmos por realizar uma pesquisa com os tutores, tivemos a intenção de observar a dinâmica de funcionamento do Curso de licenciatura em Ciências Biológicas da UEM na modalidade EAD pela visão dos tutores. Muitos assuntos determinados pelos coordenadores ou vivenciados por alunos tem um aspecto diferenciado pela visão do trabalho do tutor, principalmente por se tratar de uma função nova na educação. Tem-se debatido sobre a importância do tutor para o trabalho de formação na EAD, isso ocorre devido à novidade da construção da modalidade que se esforça para se concretizar como acesso à formação de qualidade igualada ao ensino presencial já consagrado pela UEM. 
Dentre as diversas declarações dos tutores, as limitações em relação a sua função chamaram a atenção ao demonstrar que os tutores percebem as possibilidades que seu papel como tutor pode oferecer e que ainda não é aproveitado pelas instituições, como relatado pelos tutores sobre as limitações de postagem de material complementar (espaço em kb), liberdade para promover atividades avaliativas que atendam especificamente as dificuldades dos alunos. Trata-se da organização da condução do conteúdo pela visão tradicionalista, no qual o professor é o centro do saber.

Infelizmente o professor ainda é visto dessa forma, comprometendo o auxílio para a formação dos alunos que tem a internet disponível para estudar. Demonstrar os diversos caminhos em que o conhecimento pode ser construído, também é responsabilidade das instituições de ensino, principalmente na modalidade a distância, se organizando para capacitar seus alunos a serem reflexivos e críticos, a fim de selecionar as informações que estão a sua disposição na internet para a construção de seu conhecimento.

Além disso, outros detalhes foram levantados pelos tutores, como a falta de formação específica da equipe de apoio pedagógico da UEM para lidar com a EAD. Isso foi observado ao se referirem sobre a organização da estrutura das vídeo-aulas e web conferências, confirmando que as necessidades da EAD são diferentes das necessidades do ensino presencial, por isso, não podem se sujeitar aos mesmos moldes tradicionais de ensino.

Entendemos que a $\mathrm{EAD}$ é uma modalidade de ensino que veio para levar formação de qualidade a todos, permitindo que essas pessoas possam ter a oportunidade de mudar as suas vidas. Entretanto, é preciso entender quais os elementos da estrutura atual oferecida pela UEM funcionam, quais devem ser melhorados e como devem ser melhorados, com a contribuição da opinião de quem também é responsável pela formação dos alunos.

\section{NOTAS}

1. Trata-se de um pacote de software para a produção de cursos e web sites em internet, é fornecido gratuitamente como software Open Source. 


\section{REFERÊNCIAS BIBLIOGRÁFICAS}

Alves-Mazzotti, A. J. (1988). O método nas ciências sociais. In A. J. AlvesMazzotti. O método nas ciências naturais e sociais: pesquisa quantitativa e qualitativa. São Paulo.

Bardin, L. (2004). Análise de conteúdo. Lisboa: Edições 70.

Barrenechea, C. A. (2003). A formação da identidade do aluno na educação a distância: reflexões para um debate. Educar, 117-131.

Belloni, M. L. (2003). Educação a distância. Campinas: Autores associados.

Bogdan, R. C., e Biklen, S. K. (1994). Investigação Qualitativa em Educação: uma introdução à teoria e aos métodos. Porto: Porto Editora.

Brasil. Lei de Diretrizes e Bases da Educação Nacional. (1996). Lei $n^{o}$ 9394. 20 de dezembro de 1996.

Brasil. Ministério da Educação. (2001). Proposta de diretrizes para a formação inicial de professores da educação básica em cursos de nível superior. Brasília: MEC.

Cabanas, M. I. C. e Vilarinho, L. R. G. (2007). Educação a distância: tutor, professor ou tutor-professor? $5^{o}$ Encontro de educação e tecnologias de informação e comunicação. Universidade Estácio de Sá. Mestrado em Educação e Cultura contemporânea. 12 e 13 de Novembro.

Cardoso, A. L. T., e Pereira, J. B. (2010). O tutor e atividade de tutoria na educação á distância. In
M. L. F. Costa e R. M. Zanata, (Org.), Educação a distância no Brasil: aspectos históricos legais, políticos e metodológicos. Maringá: EDUEM. Fiorentini, D., Lorenzato, S. (2006). Investigação em educação matemática: percursos teóricos e metodológicos. Campinas: Autores Associados.

CAPES (2015). Atribuições tutoria. Disponível em http://uab.capes. gov.br/.

Flick, U. (2004). Uma introdução á pesquisa qualitativa. Porto Alegre: Bookman.

Machado, M. H., Castro, A. L. De B. P., Filho, C. J. R., Lepri, E. R., Andrian, I. De F., Pamphile, J. A., De Mello, J. M., Ferrarese, M. De L., Torrezan, R. T. E., e Vicentini, V. E. P. (2009). Projeto Político Pedagógico. Curso Ciências Biológicas Modalidade a distância da Universidade Estadual de Maringá, Maringá.

Peters, O. (2009). A educação a distância em transição: tendências e desafios. São Leopoldo: Editora Unisinos.

Universidade Aberta do Brasil. (2015). Bolsas. Tutores. Disponível em http://www.uab.capes.gov.br/ index.php?option=com content\&vi

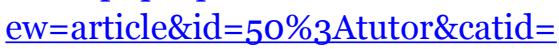
$11 \% 3$ Aconteudo\&Itemid=29.

Tonetti, F. A. (2012). Tutor é professor: Algumas considerações sobre o trabalho docente na educação a distância. SIED - Simpósio 
Internacional de Educação a distância - ENPED Encontro de Pesquisadores em Educação a Distância. UFSCAR 10 a 22 de Setembro.

Torres, P. L., e Irala, E. A. (2007). Aprendizagem colaborativa. In P. L. Torres (Org.), Algumas vias para entretecer o pensar e o agir. Curitiba: SENAR-PR.

Souza, R. R. (2000). Aprendizagem Colaborativa em Comunidade
Virtuais. Dissertação de Mestrado. Programa de Pós Graduação em Engenharia de Produção. Universidade Federal de Santa Catarina.

Souza, M. B. (Agosto, 2014). Integrando Fundamentos da EaD, Conteúdos Matemáticos e Tecnologia no Curso de Formação Continuada de Tutores de Souza. XI Congresso Brasileiro de Ensino Superior a Distância, Florianópolis, pp. 3348-3358.

\section{PERFIL ACADÊMICO Y PROFESSIONAL DE LOS AUTORES}

Thaise Francielle de Sousa Roth. Licenciada em Ciências Biológicas pela Universidade Estadual de Maringá - PR (2007). Especialista em Pesquisa Educacional, área de Fundamentos da Educação pela Universidade Estadual de Maringá (2009). Mestra em Ensino de Ciências pelo Programa de Pós- Graduação da Universidade Estadual de Londrina (2014), COM pesquisa desenvolvida na linha de formação de professores reflexivos. Atualmente é Professora na Educação Básica, Ensino Superior na modalidade a distância. E participante do grupo de estudos de Ensino de Ciências e Cultura.

E-mail: thaise.roth@gmail.com

Dulcineia Ester Pagani Gianotto. Possui graduação em Ciências Físicas e Biológicas pela Universidade Estadual de Maringá (1975), especialização em Didática e Metodologia de Ensino, Mestrado em Educação pela Universidade do Oeste Paulista (2000) e Doutorado em Educação para a Ciência pela Universidade Estadual Paulista Júlio de Mesquita (UNESP- 2008). Atualmente é professora adjunta da Universidade Estadual de Maringá, Coordenadora adjunta do curso de Ciências Biológicas a Distância e do Curso de Especialização Ensino-aprendizagem de Ciências e Biologia. Tem experiência na área de Educação, com ênfase em Formação de Professores e Tecnologia Educacional, atuando principalmente nos seguintes temas: ensino-aprendizagem, aprendizagem colaborativa, educação ambiental, recursos computacionais, informática educacional.

E-mail: depgianoto@uem.br 


\section{DIRECCIÓN DE LOS AUTORES}

Universidade Estadual de Maringá

Avenida Colombo, 5790

Jardim Universitário, Maringá

PR, 87020-900, Brasil

Fecha de recepción del artículo: 01/11/2014

Fecha de aceptación del artículo: 28/01/2015

\section{Como citar este artículo:}

De Sousa Roth, T. F., y Pagani Gianotto, D. E. (2015). Educação a distância: dificuldades dos tutores do primeiro curso licenciatura de Ciências Biológicas da Universidade Estadual de Maringá - PR. RIED. Revista Iberoamericana de Educación a Distancia, 18 (2), 299-323. doi: http://dx.doi.org/10.5944/ ried.18.2.13422. 